\title{
Description of a new species, Pintomyia dissimilis nov. sp., a phlebotomine fossil from Dominican Republic amber (Diptera: Psychodidae: Phlebotominae) José Dilermando Andrade Filho ${ }^{1}$, Paula Cavalcante Lamy Serra e Meira1, Cristiani de Castilho Sanguinette ${ }^{1}$ and Reginaldo Peçanha Brazil*2
}

\author{
Address: ${ }^{1}$ Instituto René Rachou-Fiocruz, Av. Augusto de Lima 1715, CEP 30190-002 Belo Horizonte, MG, Brazil and ${ }^{2}$ Departamento de \\ Bioquímica e Biologia Molecular, Instituto Oswaldo Cruz-Fiocruz, Rio de Janeiro, RJ, Brazil \\ Email: José Dilermando Andrade Filho - jandrade@cpqrr.fiocruz.br; Paula Cavalcante Lamy Serra e Meira - paulameira@cpqrr.fiocruz.br; \\ Cristiani de Castilho Sanguinette - cristiani@cpqrr.fiocruz.br; Reginaldo Peçanha Brazil* - rpbrazil@ioc.fiocruz.br \\ * Corresponding author
}

Published: 14 May 2009

Parasites \& Vectors 2009, 2:25 doi:10.1 186/1756-3305-2-25

This article is available from: http://www.parasitesandvectors.com/content/2/1/25

(C) 2009 Filho et al; licensee BioMed Central Ltd.

This is an Open Access article distributed under the terms of the Creative Commons Attribution License (http://creativecommons.org/licenses/by/2.0), which permits unrestricted use, distribution, and reproduction in any medium, provided the original work is properly cited.
Received: 8 May 2009

Accepted: 14 May 2009

\begin{abstract}
Background: Phlebotomine sandflies are the vectors of etiological agents of leishmaniases in several areas of the world. In the Neotropical Region, the biodiversity of these insects is more than other regions, probably due the long evolutionary period of this group. Miocene amber from Dominican Republic, currently, has a record of 14 extinct species of Phlebotomine sandflies.

Results: This paper describes a new fossil species of phlebotomine sandfly from amber found in Dominican Republic. This new species is based on morphological characters of a male such as $5^{\circ}$ palpomere longer than $3^{\circ}+4^{\circ}$, three well-developed spines in the gonostyle, lateral lobe longer than gonocoxite and permit inclusion of the new species in the genus Pintomyia, series serrana. The paramere, with a curvature in the ventral margin, of the middle of the structure, separates the new species from the others fossils or extant species.
\end{abstract}

Conclusion: The new species described in the present study named Pintomyia dissimilis nov. sp. is well differenciated from all known species in this genus.

\section{Background}

Several tropical diseases are transmitted by insects and among them is included the leishmaniases, a group of diseases which the aethiological agents are species of parasite of the genus Leishmania. Phlebotominae sandflies are responsible for the transmission among vertebrate hosts. Transmission occurs during blood feeding of females and, up to now, around 30 species are known to be involved in the transmission of the disease [1].
This host/parasite is very old being recorded in the Cretaceous and Miocene periods, where extinct sandflies in amber have been found to be associated with protozoa described as belonging to the genus Paleoleishmania $[2,3]$. This last record is related to amber of the Dominican Republic in the Hispaniola Island, Caribbean region of Central America.

To date, in the New World, fifteen species of fossil sandflies had been formally described and most are from the Dominican Republic and only one from Mexico. All the 
species are within the genera Pintomyia Costa Lima, 1932; Micropygomyia Barretto, 1962; and Psathyromyia Barretto, $1962[4,5]$.

The objective of this study was to carry out a description of one species of phlebotomine sandflies from the Dominican Republic, based on a holotype male, enclosed in amber.

\section{Methods}

The description of the fossil species was based on direct observation under the optical microscope of the holotype specimen. The piece of amber measuring 0.9 by 0.8 by 0.5 $\mathrm{mm}$, containing the male holotype and one flea. The insects were examined under the microscope and measured using an ocular micrometer calibrated for this purpose. Drawings were made using a microscope with the aid of a camera lucida and photographs taken with Konica digital equipment with a definition of 8.0 megapixels, the photographs being taken directly through the eyepiece of the microscope. The measurements are given in micrometers. Some morphological details that help to distinguish fossil from extant species have been provided. The classification system of Galati [6] was used.

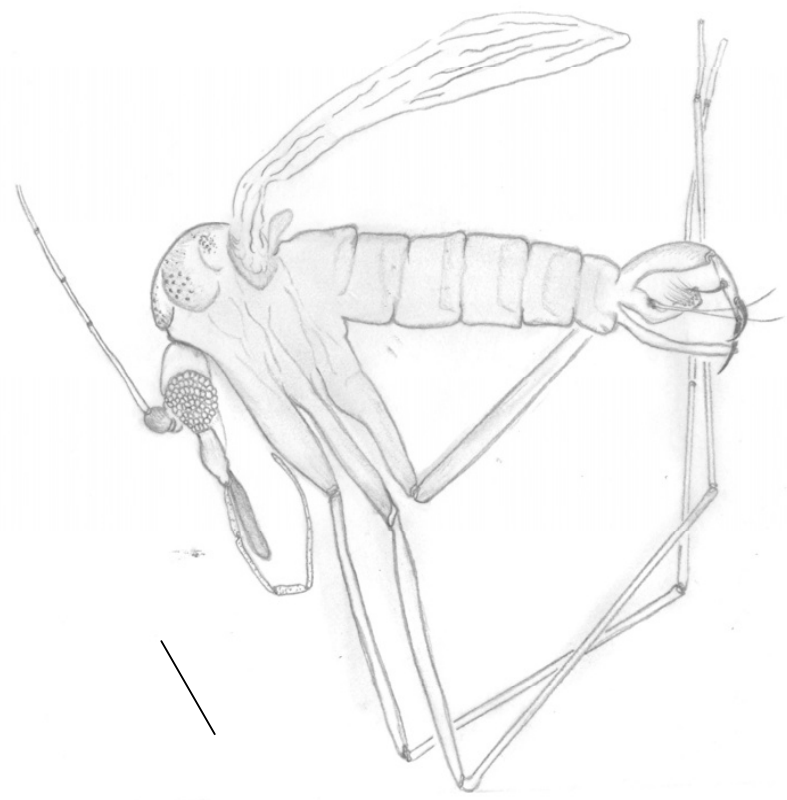

Figure I

drawing of Pintomyia dissimilis nov. sp. Bar $=250 \mu \mathrm{m}$.

\section{Results}

Description of Pintomyia dissimilis nov. sp. (Figs I, 2 and 3) Holotype male

Total length 2.029. The coloration of the insect was indistinguishable.

\section{Head (lateral view)}

Clypeus $124 \mu \mathrm{m}$ and labrum-epipharynx $235 \mu \mathrm{m}$ long. Flagellomeres measurements: AIII 262; AIV 124; AV 110, AXVI and AXV lost in holotype. Interocular distance was not measured due to the lateral position of the head. Palpal formula 1.4.2.3.5; palpomere lengths as follows: $1^{\circ}$ $28,2^{\circ}-138,3^{\circ}-152,4^{\circ}-83,5^{\circ}-359$. Ascoids, papillae and Newstead's spine not visible.

\section{Cervix}

Ventro-cervical sensillae could not be observed.

\section{Thorax}

Hind femur without row spine. Length of femora, tibia, basitarsi and tarsi II+III+IV+V: on foreleg 718, 800, 593 and, $718 \mu \mathrm{m}$; midleg 745, 952, and $662 \mu \mathrm{m}$ (tarsi II+III+IV+V lost); hindleg 772, 1.132, 745 and, $718 \mu \mathrm{m}$. Due the wing position, was impossible to measure the veins sections, width and length, but Sc is free.

\section{Abdomen}

Gonocoxite $248 \mu \mathrm{m}$ and 55 width, without tuft of bristles. Gonostyle $207 \mu \mathrm{m}$, presenting three developed spines, of which one apical, one internal on the basal third and the other external implanted close to the apical. Pre-apical bristle absent. Paramere $221 \mu \mathrm{m}$ long, presenting strong curvature in elbow-shaped in the median region of the ventral margin and a group of small bristles at its apex. Lateral lobe long, measuring 290 length by 28 width. Lat-

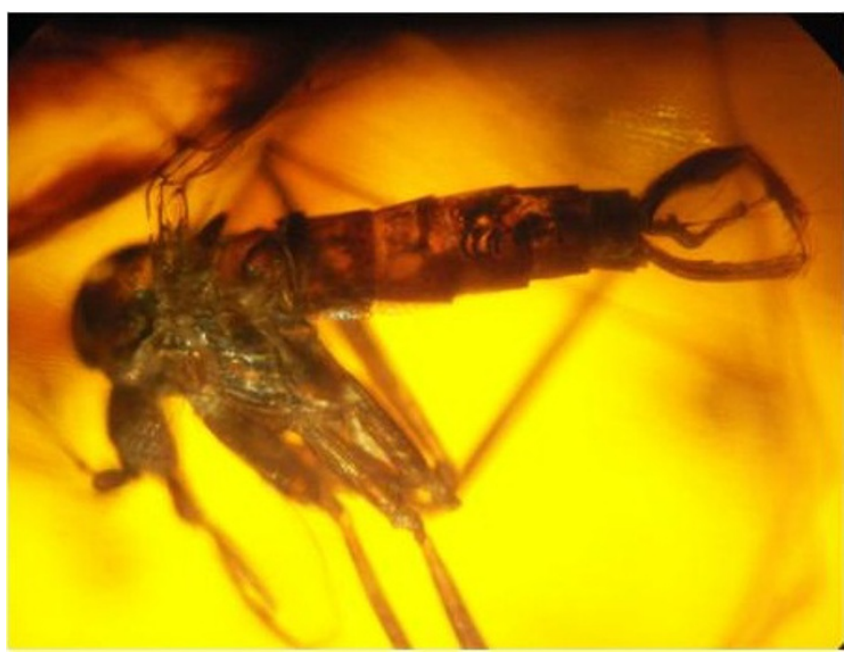

Figure 2

Pintomyia dissimilis nov. sp. - general aspect. 


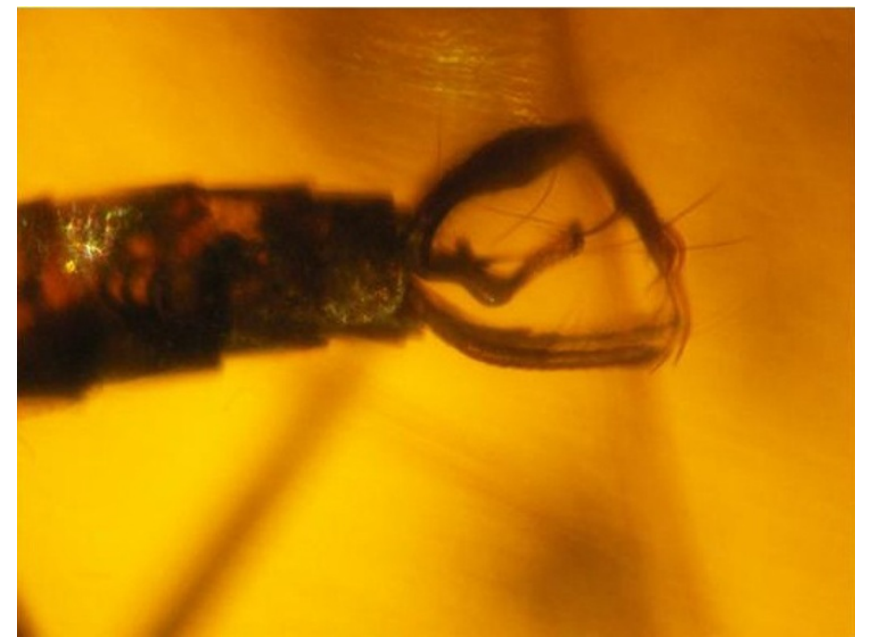

Figure 3

Pintomyia dissimilis nov. sp. - terminalia showing the different paramere.

eral lobe/gonocoxite 1.17: 1 . Is not visible the ejaculatory pump and genital filament throughout its length. Part of this is out of abdomen, leaving the aedeagus, the exposed area measured $304 \mu \mathrm{m}$, and the tip is simple.

\section{Derivatio nominis}

From the Latim dissimilis (= different) in reference to the different paramere of this species.

\section{Type Material}

One male holotype specimens in Miocene amber from Dominican Republic, north of Santiago, deposited in the Collection of phlebotomine of the Instituto René Rachou (Fundação Oswaldo Cruz), Belo Horizonte, MG, Brazil. In accordance with section 8.6 of the ICZN's International Code of Zoological Nomenclature, we have deposited copies of this article at the following five publicly accessible libraries: Natural History Museum, London, UK; American Museum of Natural History, New York, USA; Museum National d'Histoire Naturelle, Paris, France; Russian Academy of Sciences, Moscow, Russia; Academia Sinica, Taipei.

\section{Discussion}

Although the ascoids have not been displayed, as well as the papillae and Newstead spines, the character set, such as palpomere 5 longer than $3+4$; gonostyle with three spines, paramere simple and lateral lobe longer than the gonocoxite permit the specimen to be to included a new species in the genus Pintomyia. The absent of row spine in the hindfemur exclude the new species of the Pintomyia sensu stricto. Pintomyia dissimilis nov. sp. is close to Pifanomyia subgenus, series serrana, in which some species present three spines on the gonostyle in the same arrangement as this new fossil species.

Four extant species in series serrana have three well developed spines in the gonostyle, i.e. Pintomyia orestes (Fairchild \& Trapido, 1950), Pintomyia christophei (Fairchild \& Trapido, 1950), Pintomyia diazi (Gonzalves \& Garcia, 1981), and Pintomyia novoae (Gonzalves \& Garcia, 1981). All these species present tufts of bristles in the gonocoxite, absent in the fossil species.

Of 14 male fossil species described, 10 belong to the genus Pintomyia [5]. Pintomyia paleopestis (Peñalver \& Grimaldi, 2005) and Pintomyia brazilorum Andrade Filho, Galati \& Falcão, 2006 present only two developed spines in the gonostyle $[7,8]$ while in Pintomyia falcaorum Brazil \& Andrade Filho, 2002, Pintomyia killickorum (Andrade Filho, Falcão, and Brazil, 2004) Pintomyia filipalpis (Peñalver \& Grimaldi, 2005), Pintomyia paleotownsedi Andrade Filho, Falcão, Galati, and Brazil, 2006, Pintomyia paleotrichia Andrade Filho, Brazil, Falcão, and Galati, 2007, and Pintomyia dominicana Andrade Filho, Galati \& Brazil, 2009 this structure has four spines [5,7,9-12]

Only two phlebotomine fossil species have three developed spines in the gonostyle, i. e., Pintomyia succini (Peñalver \& Grimaldi, 2005) and Pintomyia miocena (Peñalver \& Grimaldi, 2005) [7]. Pintomyia dissimilis nov. sp. differ from both by the aspect of the paramere, that presents a strong curvature, absent in the other species.

One species, Lutzomyia adketis Poinar Jr 2008 was described based in one female, with the following characteristics: sc forked with the branches meeting the costa and radius veins and the shape and size of the spatulate rods on the ninth sternite [13]. Although the principals vein sections are not described, the sc is free in Pintomyia dissimilis and can be used to separate both species.

\section{Conclusion}

The new species described in the present study named Pintomyia dissimilis nov. sp. is well differenciated from all known species in this genus. With the description of the new species, the fauna of phlebotomine sandflies fossils contains 16 species, 11 belong to the genus Pintomyia.

\section{Competing interests}

The authors declare that they have no competing interests.

\section{Authors' contributions}

JDAF, PCLSM, CCS and RPB participated in morphological analysis of the specimens. CCS and PCLSM did drawing and measurements of the new species. JDAF and RPB drafted the manuscript. All authors read and agreed with this manuscript. 


\section{References}

I. Killick-Kendrick R: Phlebotomine vectors of the leishmaniasis: a review. Med Vet Entomol 1990, 4: I-24.

2. Poinar G Jr: Palaeomyia burmitis gen. n., sp. n. (Phlebotominidae: Diptera) a new genus of Cretaceous sandflies with evidence of blood sucking habits. Proc Entomol Soc Wash 2004, I 06:598-605.

3. Poinar G Jr, Poinar R: Paleoleishmania proterus n. gen., n. sp., (Trypanosomatidae: Kinetoplastida) from cretaceous burmese amber. Protist 2004, I 55:305-310.

4. Andrade Filho JD, Galati EAB, Falcão AL, Brazil RP: Description of Micropygomyia brandaoi sp. nov. (Diptera: Psychodidae: Phlebotominae), a fossil phlebotomine from the Dominican Republic. Mem Inst Oswaldo Cruz 2008, I 03:344-346.

5. Andrade Filho JD, Galati EAB, Brazil RP: Review of the American Fossil Phlebotominae (Diptera: Psychodidae), with a Description of Two New Species. J Med Entomol in press.

6. Galati EAB: Classificação de Phlebotominae. In Flebotomíneos do Brasil Edited by: Rangel EF, Lainson R. Rio de Janeiro, Fiocruz; 2003:23-53.

7. Peñalver E, Grimaldi D: Assemblages of mammalian hair and blood-feeding midges (Insecta: Diptera: Psychodidae: Phlebotominae) in Miocene amber. Trans R Soc Edin: Earth Sci 2005, 96: $177-195$.

8. Andrade Filho JD, Galati EAB, Brazil RP: Description of Pintomyia (Pifanomyia) brazilorum sp. nov. a new fossil species from the Dominican Republic (Diptera: Psychodidae: Phlebotominae). Mem Inst Oswaldo Cruz 2006, I 0 I: I4 I-I42.

9. Brazil RP, Andrade Filho JD: Description of Pintomyia (Pifanomyia) falcaorum sp. n. (Diptera: Psychodidae: Phlebotominae), a fossil sand fly from Dominican Amber. Mem Inst Oswaldo Cruz 2002, 97:501-503.

10. Andrade Filho JD, Falcão AL, Brazil RP: A new phlebotomine fossil species Trichopygomyia killickorum sp. n. (Diptera: Psychodidae), found in the Dominican Republic amber. Parasite 2004, I I:71-73.

II. Andrade Filho JD, Falcão AL, Galati EAB, Brazil RP: Pintomyia (Pifanomyia) paleotownsendi, a new species sand fly from the Miocene amber of Dominican Republic (Diptera: Psychodidae: Phlebotominae). Mem Inst Oswaldo Cruz. 2006, I 0 I (suppl 2):57-58.

12. Andrade Filho JD, Brazil RP, Falcão AL, Galati EA: Description of Pintomyia (Pifanomyia) paleotrichia, a Miocene period new species from the Dominican Republic (Diptera: Psychodidae: Phlebotominae). Mem Inst Oswaldo Cruz. 2007, I 02(8):901-903.

13. Poinar G Jr: Lutzomyia adiketis sp. n. (Diptera: Phlebotomidae), a vector of Paleoleishmania neotropicum sp. n. (Kinetoplastida: Trypanosomatidae) in Dominican amber. Parasit Vectors 2008, I:22.
Publish with Bio Med Central and every scientist can read your work free of charge

"BioMed Central will be the most significant development for disseminating the results of biomedical research in our lifetime. "

Sir Paul Nurse, Cancer Research UK

Your research papers will be:

- available free of charge to the entire biomedical community

- peer reviewed and published immediately upon acceptance

- cited in PubMed and archived on PubMed Central

- yours - you keep the copyright

Submit your manuscript here:

http://www.biomedcentral.com/info/publishing_adv.asp
BioMedcentral 